\title{
Utilização dos bioestimuladores de colágeno na harmonização orofacial
}

\author{
- Natália Barbosa de Lima Departamento de Odontologia, Universidade Maurício de Nassau, Recife, PE, Brasil \\ - Marilia de Lima Soares Departamento de Odontologia, Universidade Maurício de Nassau, Recife, PE, Brasil
}

RESUMO | Este trabalho aborda brevemente o processo de envelhecimento facial para revisar e discutir a utilização dos bioestimuladores de colágeno empregados na harmonização orofacial visando o rejuvenescimento da face. Método: Foi pesquisado nas bases SciELO, BIREME e PubMed por artigos publicados até 2019, nos idiomas inglês e português. Os critérios de inclusão englobaram artigos originais que analisaram ou discutiram sobre os preenchedores cutâneos com capacidade bioestimuladora e o processo de envelhecimento facial; no total, 72 artigos foram considerados elegíveis para esta revisão de literatura. Discussão: No mercado dermatológico existem quatro preenchedores cutâneos (ácido poli-L-láctico, hidroxiapatita de cálcio, policaprolactona e polimetilmetacrilato) que possuem a faculdade de estimular a neocolagênese a partir de uma resposta inflamatória subclínica localizada por parte do corpo do paciente. Cada produto possui suas particularidades quanto à composição, o tempo de início do efeito, e a durabilidade. De acordo com a literatura, todos os preenchedores cutâneos são considerados eficazes e seguros, podendo ser utilizados por profissionais devidamente capacitados. Conclusão: mesmo os bioestimuladores de colágeno sendo excelentes materiais capazes de prevenir ou reverter os efeitos do envelhecimento facial, não existe, porém, um bioestimulador dérmico perfeito, pois todos podem gerar efeitos adversos, devendo o profissional saber selecionar o produto ideal para o tratamento de cada paciente.

DESCRITORES | Preenchedores dérmicos; Colágeno; Hidroxiapatita de cálcio; Polimetilmetacrilato, Bioestimulador de colágeno.

ABSTRACT | Use of collagen biostimulators in orofacial harmonization • This study briefly addresses the facial aging process, reviews, and discusses the use of collagen biostimulators used in orofacial harmonization in search of facial rejuvenation. Methods: Articles published until 2019 in SciELO, BIREME and PubMed in English and Brazilian Portuguese were verified. The inclusion criteria were: original articles that analyze or discuss skin fillers with biostimulatory capacity, and the facial aging process. A total of 72 articles that met the inclusion criteria was found. Discussion: In the dermatological market there are four skin fillers (polyL-lactic acid, calcium hydroxyapatite, polycaprolactone and polymethylmethacrylate) that have the mechanism of action of stimulating neocolagenesis by localized subclinical inflammatory response from the host. Each product has its particularities as to its composition, onset time, and durability. According to the literature, they are generally considered to be effective and safe, and can be used by properly trained professionals. Conclusion: Collagen biostimulators are excellent materials with the ability to prevent or reverse the effects of the facial aging process. However, there is still no perfect dermal biostimulator, as everyone can be associated with adverse effects, and the professional must know how to select the ideal product for treating each patient.

DESCRIPTORS | Dermal Fillers; Collagen; Calcium Hydroxyapatite; Polymethyl Methacrylate; Collagen biostimulator.

AUTOR CORRESPONDENTE | Natália Barbosa de Lima Departamento de Odontologia, Universidade Maurício de Nassau • Rua Joaquim Nabuco, 615 Recife, PE, Brasil • 50010-480 E-mail: nataliabarbosalima1@gmail.com

- Recebido 20 janeiro 2020 • Aceito 24 abril 2020

- DOI: http://dx.doi.org/10.11606/issn.2357-8041.clrd.2020.165832 


\section{INTRODUÇÃO}

A beleza sempre foi demasiadamente importante para os indivíduos, o belo sempre foi admirado pela sociedade. Dessa forma, a busca por tal e consequentemente sua satisfação estética aumenta constantemente, tendo significante influência sobre a autoestima e bem estar do ser humano. Diante disso, a harmonização orofacial está em um momento de grande evidência, tendo como principal objetivo harmonizar a face e os dentes estética e funcionalmente com a boca através de procedimentos estéticos, sejam eles cirúrgicos ou não. ${ }^{1}$

Frente a isso, a odontologia moderna possui um papel relevante nessa área, pois além de prevenir e intervir em doenças, também atua sobre fatores estético-faciais legalmente permitidos ao cirurgiãodentista especialista em Harmonização Orofacial - o uso da toxina botulínica, de preenchedores faciais e agregados leucoplaquetários autólogos na região orofacial, em estruturas anexas e afins, fazer intradermoterapia e a utilização de biomateriais indutores percutâneos de colágeno, entre outros procedimentos de harmonização orofacial -, que fazem parte de sua competência, segundo a resolução No 198/2019 do Conselho Federal de Odontologia. ${ }^{2}$

Os preenchedores faciais é um dos métodos mais procurados para melhorar a estética facial, a fim de proporcionar uma face mais jovial e natural, permitindo a restauração de volumes e contornos perdidos no processo de envelhecimento, que provoca diminuição gradativa da síntese de colágeno, resultando em uma pele mais fina e elástica..$^{3-5}$

O objetivo deste trabalho foi abordar brevemente o processo de envelhecimento facial e descrever a utilização dos bioestimuladores de colágeno empregados na harmonização orofacial em busca do rejuvenescimento facial.

\section{METODOLOGIA}

Como metodologia, foi pesquisado nas bases de dados SciELO, BIREME e PubMed, artigos publicados até 2019, nos idiomas inglês e português. Os critérios de inclusão englobaram artigos originais que analisaram ou discutiram sobre os preenchedores cutâneos com capacidade bioestimuladora e o processo de envelhecimento facial. Um total de 72 artigos foram considerados elegíveis para inclusão nesta revisão de literatura.

\section{REVISÃO DE LITERATURA Envelhecimento facial}

Para uma eficaz recuperação ou manutenção dos contornos faciais, é necessário entendermos como se dá o envelhecimento da face. $O$ envelhecimento facial é consequência de múltiplos fatores intrínsecos e extrínsecos, que são interrelacionados e que contribuem de forma significante para a manifestação dos principais sinais do envelhecimento, como as rugas, as manchas, alterações de textura, flacidez, sulcos ou queda da pálpebra superior, entre outros. ${ }^{5}$

O envelhecimento extrínseco, também chamado de fotoenvelhecimento, se deve às excessivas e repetitivas exposições aos raios ultravioletas (UVA, UVB e luz visível), que estimulam a formação dos radicais livres, e de outros fatores como poluição, tabagismo, álcool e hábitos nutricionais. ${ }^{4}$ O envelhecimento intrínseco ou cronológico é influenciado por fatores genéticos, sendo natural e inevitável. Com a idade, inicia-se um declínio das funções vitais do corpo, a redução das renovações celulares, os déficits hormonais, a diminuição de melanócitos, a deformação das fibras elásticas e redução da síntese da principal proteína responsável pela sustentação da pele, o colágeno, resultando em uma pele mais fina, com rugas e linhas. ${ }^{4-6}$

Sugere-se na literatura que existem quatro pilares estéticos interligados ao processo de envelhecimento facial - remodelação óssea, perda de gordura subdérmica, ação muscular e envelhecimento da pele -, dessa forma, uma mudança em uma área pode influenciar grandemente nos tecidos vizinhos, 
tratando-se de um efeito cascata. ${ }^{3,7,8} \mathrm{O}$ processo de envelhecimento resulta em modificações nas proporções das estruturas faciais, durante a juventude o rosto apresenta uma forma de um trapézio invertido, com o terço médio da face bem definido, e com o passar do tempo os contornos e o volume facial são perdidos, tornando a face com forma de um quadrado, a chamada "quadralização" facial. ${ }^{3}$

\section{Bioestimuladores de colágeno}

Diante dos estudos acerca dos pilares do envelhecimento facial, os procedimentos minimamente invasivos revolucionaram o tratamento para o rejuvenescimento facial: os preenchedores dérmicos expandiram o seu conceito para não apenas tratar das linhas finas e rugas, mas passou a incluir a correção da perda de volume e o aumento da face envelhecida. ${ }^{9}$ Dentre os preenchedores faciais, os bioestimuladores ganharam popularidade no mercado dermatológico, tendo como principal objetivo melhorar o aspecto cutâneo, agindo de forma ativa nas camadas mais profundas da pele, além de também devolver o volume facial perdido, através do estímulo a formação de novo colágeno dérmico. ${ }^{5}$

Os bioestimuladores são classificados quanto à durabilidade e a absorção pelo organismo, existindo os biodegradáveis, que tem sua absorção pelo próprio organismo, através de mecanismos fagocitários naturais, e semipermanentes, que possuem duração entre 18 meses e 5 anos. ${ }^{5,6}$ Dentro dessa categoria estão o ácido PoliL-láctico (PLLA), hidroxiapatita de cálcio (CaHA), e a policaprolactona (PCL). ${ }^{10}$ Também existe o bioestimulador classificado como não biodegradável, que não é fagocitado e permanece indefinidamente no organismo. Nessa categoria está o polimetilmetacrilato (PMMA). ${ }^{5}$ (Tabela 1)

TABELA 1 | Comparação dos preenchedores dérmicos bioestimuladores

\begin{tabular}{|c|c|c|c|c|}
\hline Produto & Classificação & Mecanismo de ação & Indicações & Contra indicações \\
\hline Ácido Poli-L-láctico & Semipermanente & \multirow{3}{*}{$\begin{array}{l}\text { As microesferas } \\
\text { que compõem o } \\
\text { produto, estimulam a } \\
\text { neocolagênese a partir de } \\
\text { uma resposta inflamatória } \\
\text { subclínica localizada, } \\
\text { resultando no aumento } \\
\text { de fibras colágenas pelos } \\
\text { fibroblastos, além disso, } \\
\text { também servem como } \\
\text { arcabouço para os novos } \\
\text { tecidos. }\end{array}$} & $\begin{array}{l}\text { Lipoatrofia facial associada } \\
\text { ao Vírus da Imunodeficiência } \\
\text { Humana; } \\
\text { Região temporal, malar, sulcos } \\
\text { nasolabiais, ângulo mandibular, } \\
\text { linha do queixo e correção de } \\
\text { linhas de marionetes; } \\
\text { Correção de cicatrizes de acne. }\end{array}$ & $\begin{array}{l}\text { - Lábios; } \\
\text { - Região perioral;' } \\
\text { - Região periorbitária; } \\
\text { - Região frontal; } \\
\text { - Combinação com } \\
\text { preenchedor } \\
\text { permanente. }\end{array}$ \\
\hline $\begin{array}{c}\text { Hidroxiapatita de } \\
\text { Cálcio }\end{array}$ & Semipermanente & & $\begin{array}{l}\text { Lipoatrofia facial associada } \\
\text { ao Vírus da Imunodeficiência } \\
\text { Humana; } \\
\text { Área nasal, comissura } \\
\text { labial, rugas peribucais, } \\
\text { malar/zigomático, contorno } \\
\text { mandibular; } \\
\text { Região temporal, terço médio } \\
\text { da face, prega mentoniana, } \\
\text { mento; } \\
\text { Correção de cicatrizes de acne. }\end{array}$ & $\begin{array}{l}\text { - Glabela; } \\
\text { Área periorbicular; } \\
\text { Lábios; } \\
\text { Combinação com } \\
\text { preenchedor } \\
\text { permanente. }\end{array}$ \\
\hline Policaprolactona & Semipermanente & & $\begin{array}{l}\text { Correção de dobras } \\
\text { nasolabiais; } \\
\text { Áreas superior, média e } \\
\text { inferior da face. }\end{array}$ & $\begin{array}{l}\text { Região periórbita } \\
\text { (pálpebras, olheiras e } \\
\text { “pés de galinha”); } \\
\text { Glabela; } \\
\text { Lábios. }\end{array}$ \\
\hline
\end{tabular}


Tabela 1 | continuação

\begin{tabular}{|c|c|c|c|c|}
\hline Produto & Classificação & Mecanismo de ação & Indicações & Contra indicações \\
\hline Polimetilmetacrilato & Permanente & $\begin{array}{l}\text { As microesferas } \\
\text { que compõem o } \\
\text { produto, estimulam a } \\
\text { neocolagênese a partir de } \\
\text { uma resposta inflamatória } \\
\text { subclínica localizada, } \\
\text { resultando no aumento } \\
\text { de fibras colágenas pelos } \\
\text { fibroblastos, além disso } \\
\text { essas servem como } \\
\text { arcabouço para os novos } \\
\text { tecidos. A diferença é } \\
\text { que as microesferas não } \\
\text { são degradadas pelo } \\
\text { organismo. }\end{array}$ & $\begin{array}{l}\text { Dobras nasolabiais; } \\
\text { Correção de cicatrizes de } \\
\text { acne; } \\
\text { Defeitos dérmicos de tecidos } \\
\text { moles e ósseos; } \\
\text { Lipoatrofia facial associada } \\
\text { ao Vírus da Imunodeficiência } \\
\text { Humana. }\end{array}$ & $\begin{array}{l}\text { Lábios; } \\
\text { - Região periorbicular; } \\
\text { - Portadores de Hepatite C. }\end{array}$ \\
\hline
\end{tabular}

\section{ÁCIDO POLI-L-LÁCTICO}

O PLLA (Sculptra ${ }^{\circledR}$ ou New-Fill ${ }^{\circledR}$ ) é um polímero biocompatível injetável, totalmente sintético composto por microparticulas biodegradáveis e reabsorvíveis, que estimula a neogênese do colágeno. ${ }^{11-15}$

\section{Composição e mecanismo de ação}

Trata-se de polímero sintético produzido a partir da fermentação do açúcar proveniente do milho. ${ }^{16,17}$ É composto por micropartículas de PLLA, que medem entre 40-63 $\mu \mathrm{m}$ de diâmetro, sendo o ingrediente ativo do produto; carboximetilcelulose de sódio, que age como um emulsificante para melhorar a reidratação e o manitol não pirogênico, que ajuda na liofilização das particulas. . $^{8,12,18,19}$

Seu mecanismo de ação para estimular a neocolagênese começa com uma resposta inflamatória subclínica localizada. ${ }^{8,12,14,18}$ Uma vez injetado, as grandes partículas de PLLA atraem um grande número de macrófagos (que por não conseguirem fagocitar as partículas, unem-se formando outro tipo de célula inflamatória maior, chamada de Célula Gigante Multinuclear), linfócitos e fibroblastos. ${ }^{18,20}$ Uma cápsula é formada em torno de cada microesfera individual à medida que o PLLA é metabolizado, resultando no aumento da deposição das fibras de colágeno pelos fibroblastos, tendo como resultado final um aumento subsequente da espessura dérmica. ${ }^{8,15,18,21}$

Após sua aplicação, mudanças são prontamente observáveis, correspondentes ao volume do diluente do produto, no entanto, essas desaparecerão com cerca de dois a três dias, até absorção completa do diluente. Isto acontece devido o PLLA não ser de fato um agente preenchedor, e sim um estimulador de colágeno do próprio hospedeiro, que tem seu efeito de forma gradual e progressiva, e não imediato. , $^{8,222-24}$

Com o objetivo de caracterizar a resposta tecidual humana em indivíduos tratados com PLLA, Goldberg e colaboradores (2013) ${ }^{25}$ realizaram um estudo examinando a nova formação de colágeno tipos I e III e reação inflamatória, através de biópsias das áreas injetadas. Os resultados mostraram que o nível médio de colágeno tipo I aumentou estatisticamente de forma significativa de 21,2\% no início, aos 3 meses (35,3\%) e aos 6 meses (33,7\%), no entanto, o nível de aumento de colágeno tipo III não alcançou significância estatística, sendo considerado um resultado positivo, visto que o colágeno tipo I está ligado a neocolagênese fisiológica, e o tipo III tem relação com o processo de fibrose tecidual. 


\section{Características do ácido poli-L-láctico}

Considerado um produto imunologicamente inerte e biocompatível, é apresentando a vantagem de não requerer testes pré-tratamento. ${ }^{14,15,26}$

É classificado como um preenchedor semipermanente, com resultados que perduram por cerca de 24 meses. ${ }^{5,11,14,15,18,26}$ No entanto, Rendon (2012) ${ }^{21}$ através de uma revisão retrospectiva avaliou os resultados estéticos de longo prazo de 100 pacientes injetados com PLLA, acompanhados por até 5 anos, relatou durações prolongadas até 4 anos após a correção completa, sem necessidade de retoques em alguns casos, principalmente em pacientes com menos de 55 anos de idade. Essa variabilidade na duração do efeito, está relacionada com vários fatores específicos do paciente (idade, sexo, qualidade da pele, base da estrutura óssea, fototipo e alimentação) que podem influenciar na duração total do efeito, no entanto, são necessários mais estudos acerca dessas variabilidades. ${ }^{21,27}$

É um produto biodegradável, tendo sua degradação por hidrólise não enzimática, onde os polímeros poliláticos são transformados em monômeros de ácido lático que são metabolizados em dióxido de carbono $\left(\mathrm{CO}_{2}\right)$ e água $\left(\mathrm{H}_{2} \mathrm{O}\right)$, sendo eliminado totalmente do corpo através da urina, fezes e sistema respiratório. ${ }^{11,14,16,21}$

\section{DIRETRIZES GERAIS DO PRODUTO}

É apresentado comercialmente como um pó liofilizado (sem partículas de água) em um frasco estéril, que requer reidratação antes da injeção. ${ }^{18}$ O fabricante recomenda usar $5 \mathrm{~mL}$ de água destilada para cada frasco, e manter este em repouso por pelo menos 2 horas, afim de garantir a hidratação completa. ${ }^{28}$ Contudo, Schierle e Casas (2011), ${ }^{18} \mathrm{e}$ Rendon (2012), ${ }^{21}$ baseados em suas experiências clínicas, recomendam tempo de repouso e diluições maiores, devido à significativa redução nas taxas de nodularidade, além de tornar a injeção mais fácil, uma distribuição mais uniforme do produto e menor risco de obstrução da agulha são comuns diluições com volume total entre 6 e $8 \mathrm{~mL}$, sendo $6 \mathrm{~mL}$ da suspenção de PLLA e água destilada, e $2 \mathrm{~mL}$ de lidocaína a $2 \%$ com ou sem epinefrina, que deve ser adicionada imediatamente antes da aplicação. ${ }^{5,8,10,18,19,21}$ Após a reconstituição, o produto deve permanecer em repouso durante um período de 24 a 72 horas, em temperatura ambiente e deve ser agitado vigorosamente antes da aplicação. ${ }^{5,6,18,27}$

O plano de aplicação deve ser selecionado corretamente, pois trata-se de um fator crítico para o sucesso do tratamento. $\mathrm{O}$ material pode ser aplicado em três planos distintos - supraperiosteal, subdérmico e subcutâneo -, a escolha em qual será o plano de aplicação do PLLA depende da condição do paciente. É aplicado no plano supraperiosteal em áreas com suporte ósseo, no subcutâneo onde não houver alicerce ósseo, e subdérmico em casos de frouxidão da pele. ${ }^{8,10,27,29}$

A quantidade de produto e o número de sessões para o sucesso do procedimento depende da necessidade de cada paciente, levando em consideração o grau de envelhecimento. Diante disso, pacientes mais jovens ou com rostos mais volumétricos geralmente necessitam menos sessões e menores quantidades de produto. ${ }^{27} \mathrm{O}$ resultado de um tratamento varia entre quatro e seis meses. ${ }^{16}$ Sendo assim, deve-se usar a regra de "tratar, esperar e avaliar", para guiar a necessidade de injeções subsequentes, devendo respeitar intervalos de 4 a 6 semanas entre as sessões, para diminuir o risco de efeitos adversos..$^{5,8,20,21}$

\section{Principais indicações}

Em 2004, foi o primeiro agente preenchedor aprovado pelo Food and Drug Administration (FDA) para tratamento em pacientes com lipoatrofia facial associada ao Vírus da Imunodeficiência Humana (HIV) e, em 2009, foi aprovado para tratamento com fins estéticos em pacientes imunocompetentes. . $^{11,18,30,31}$ No Brasil, o produto está disponível para uso há cerca 
de 14 anos, para tratamento em lipoatrofias associadas ao HIV e off label para finalidade estética.5,27

É considerada uma ótima alternativa para o tratamento de pacientes que precisam de uma bioestimulação tridimensional e que buscam resultados sutis, com aspecto natural., ${ }^{821}$ Diante disto, ele não é injetado diretamente em rugas, sulcos ou linhas, mas difusamente em áreas côncavas ou de sombras, causadas por perda de gordura hipodérmica e/ou subcutânea devido ao envelhecimento ou lipoatrofias associadas ao HIV, flacidez dérmica e sulco nasogenianos, buscando de fato o tratamento tridimensional, na tentativa de tratar a perda de volume. ${ }^{5,8,16,27}$ As regiões mais tratadas são temporal e zigomática, sendo também relatados casos de uso no contorno facial, sulcos nasolabiais, ângulo mandibular, linha do queixo e correção de linhas de marionetes. . $^{8,12,15,18,21,23}$

Com relação a sua utilização no tratamento de lipoatrofia facial relacionada ao HIV, Bassichis et al. (2012) ${ }^{31}$ publicaram um estudo intercalar cumulativo, o qual examinou a segurança e a eficácia do PLLA injetável em 290 indivíduos com HIV. Em 2 anos, 89,4\% dos pacientes e 95,5\% dos médicos classificaram a satisfação com o tratamento como muito boa ou excelente. Os eventos adversos mais frequentes, emergentes do tratamento foram pápulas (8,6\%), nódulos $(8,3 \%)$ e hematomas localizados $(7,2 \%)$, não sendo relatado nenhuma reação adversa grave relacionada ao produto ou ao procedimento, confirmando que o PLLA injetável é um tratamento seguro e eficaz para indivíduos com lipoatrofia facial relacionada ao HIV.

Além dessas indicações, o PLLA injetável é considerado como uma alternativa eficiente e segura no tratamento dos casos envolvendo cicatrizes de acne, tendo Sadiki e Palmisano (2009) ${ }^{32}$ relatado um caso de tratamento com PLLA injetável em uma paciente com 60 anos de idade, a qual apresentava cicatrizes profundas moderadas a grave, causadas por acne. A paciente foi tratada com um total de sete sessões de PLLA injetável, relatando melhora visível das cicatrizes de acne 6 meses após o tratamento, provando que o PLLA injetável foi bem tolerado, sendo relatado apenas inchaço mínimo durante os três primeiros dias.

\section{Contraindicações e efeitos adversos}

Com base na literatura, algumas áreas da face não são indicadas para aplicação do PLLA, devido ao grande risco de desenvolvimento de efeitos adversos no local da injeção. Essas áreas incluem: os lábios, as regiões perioral, periorbitária e frontal, pois são locais de grande mobilidade muscular, acarretando o acúmulo do produto e uma sobrecorreção no local.8,11,16

Assim como a maioria dos preenchedores dérmicos, o PLLA injetável é bem tolerado, sendo comum após sua aplicação o desconforto, hematomas, eritema ou edema no local da injeção, os quais geralmente são leves, transitórios e se resolvem espontaneamente. . $1,27,33,34^{2}$

Eventos adversos como os nódulos não inflamatórios, pápulas, granulomas e eventos vasculares, são mencionados na literatura, no entanto, complicações sistêmicas potencialmente mais sérias são muito raras. ${ }^{27,33,34} \mathrm{O}$ desenvolvimento de nódulos e pápulas são mais frequentes, mas relativamente pequeno, onde acredita-se que estejam relacionados a considerações técnicas, como acúmulo do material, devido reconstituição inadequada do produto, técnica de injeção em um plano superficial, localização ou falta de cuidados pósprocedimento. ${ }^{8,12,27}$ Afim de determinar o número e os tipos de complicações associadas aos preenchimentos de tecidos moles injetáveis, Daines e Williams (2013), ${ }^{35}$ através de uma revisão retrospectiva de 5 anos, relataram apenas 6 complicações de 811 pacientes tratados com PLLA, onde, 5 foram casos de nódulos subcutâneos e 1 caso de dermatite perioral.

Já os granulomas são considerados como uma complicação rara, com incidência menor que $0,1 \%$, que são diferenciados dos nódulos fibróticos por 
terem seu início tardio, meses ou anos após a injeção, apresentando sensibilidade, inchaço, eritema e ocasionalmente supuração. ${ }^{35-37}$ Acredita-se ser um processo de natureza sistêmica, como uma resposta exagerada ao material injetado, infecção bacteriana de crescimento lento e por formação de biofilmes. ${ }^{27,37}$ Além disso, sua associação com preenchedores permanentes é contraindicada devido grande risco de formação de granulomas, comprovado por Rendon $(2012)^{21}$ que relatou uma formação granulomatosa em um caso de combinação entre preenchedor de longa duração e preenchedor permanente. A paciente desenvolveu granulomas na testa, área glabelar e sulco nasolabial após ser injetado o PLLA nas áreas das bochechas e da mandíbula, cerca de 15 anos após o uso do silicone.

\section{HIDROXIAPATITA DE CÁLCIO}

A hidroxiapatita de cálcio (CaHA) é um bioestimulador de colágeno injetável sintético, conhecido no Brasil pelos nomes comerciais (Radiesse ${ }^{\circledR}$ ) e (Rennova ${ }^{\circledR}$ Diamond Lido) ambos aprovados pela Agência Nacional de Vigilância Sanitária (Anvisa). ${ }^{38}$

\section{Composição e mecanismo de ação}

Com relação a sua composição química, é composto principalmente pela CaHA, tendo 30\% de microesferas sintéticas de hidroxiapatita de cálcio, que são esféricas e uniformes, variando entre $25 \mathrm{e}$ $45 \mu \mathrm{m}$ de diâmetro, e 70\% de um gel transportador aquoso, composto por carboximetilcelulose de sódio, água estéril e glicerina. ${ }^{5,9,39,41}$

Quando injetada, há uma correção imediata no local, onde o gel carreador começa a ser dissipado de forma gradual cerca de 2 a 3 meses após a aplicação, deixando apenas as microesferas, as quais além de induzirem a uma resposta fibroblástica, estimulando a formação de novo colágeno, atuam como um arcabouço de sustentação para os novos tecidos formados. ${ }^{5,41,42}$
Com o objetivo de comparar a neocolagênese e produção de elastina produzida pela CaHA e pelo ácido hialurônico (HA), Yutskovskaya, Kogan e Leshunov (2014), ${ }^{43}$ realizaram um estudo histomorfológico randomizado com 24 mulheres tratadas com dose únicas de produtos, as quais foram avaliadas através de biópsias 4 e 9 meses após a aplicação, tendo os resultados evidenciado uma remodelação tecidual mais ativa nas pacientes tratadas com CaHA, em comparação com o HA.

\section{Características da hidroxiapatita}

Por ser produzida naturalmente no corpo humano, sendo encontrada nos dentes e ossos, é considerado um produto biocompatível, com alto grau de segurança, devido baixa resposta inflamatória, determinada pela característica de superfície lisa e tamanho regular das micropartículas..$^{5,6,9}$

Outra característica que a CaHA apresenta é a alta viscoelasticidade, o que significa que após a aplicação o material preenchedor permanecerá no local da injeção, sem que haja migração para outras áreas circundantes. ${ }^{5,44}$

É classificado como um preenchedor semipermanente, com duração média de 12 a 18 meses, podendo ser observado até 24 meses em alguns pacientes, no entanto, essa longevidade depende de diversos fatores, como idade, movimento dinâmico da área injetada e metabolismo do paciente..$^{5,41}$

Além dessas características, é um produto biodegradável, sendo eliminado pelo organismo através da fagocitose por macrófagos, que decompõem as microesferas em íons de cálcio e fosfato, eliminados na urina..$^{5,13}$

\section{Diretrizes gerais do produto}

Com mais de 20 anos de uso na área médica, a hidroxiapatita de cálcio é comercializada pronta para uso, em seringas descartáveis de o,8 mL e 1,5 mL, não necessitando de manuseio especial, sendo apenas 
recomendado pelo fabricante a homogeneização do produto. ${ }^{5,41}$ Devido a necessidade de anestesiar a região tratada antes da aplicação do produto, por meio de infiltração ou bloqueio regional com anestésico local, um protocolo aprovado pela FDA possibilita realizar diluições da CaHA com lidocaína, a fim de tornar a experiência mais agradável para os pacientes, e facilitando a extrusão do material através da agulha/ cânula, além de tudo diminui a distorção local causada pela aplicação prévia do anestésico local. Essa homogeneização é realizada com o auxílio de um conector Luer Lock, sendo recomendado no mínimo de 15 a 20 movimentos de mizagem. ${ }^{11,39,40}$

No que diz respeito ao plano de aplicação, a CaHA, ela deve ser injetada na derme média ou profunda, para que o estímulo do colágeno seja eficiente, sendo assim injeções dérmicas intradérmicas ou superficiais não são recomendadas, devido grande risco de causarem nódulos visíveis na derme superficial.5,9,39,41 Além disso, os resultados devem ser alcançados de forma gradual ao longo de várias sessões, sendo desaconselhável a injeção excessiva do material. ${ }^{9,41}$

\section{Principais indicações}

A hidroxiapatita de cálcio tem como principais indicações criar volumes e preencher locais que necessitam de reparo, o qual é conseguido através da bioestimulação de um novo colágeno do próprio paciente. ${ }^{5}$

Inicialmente, a hidroxiapatita de cálcio recebeu aprovação do FDA em 2006 para o tratamento de rugas e dobras nasolabiais, além de lipoatrofia facial associada ao HIV, tornando-se o segundo material preenchedor a receber a aprovação do FDA..$^{9,30}$ Demonstrando os resultados satisfatórios nesses casos, Rauso et al (2013) ${ }^{45}$ realizaram um estudo clínico prospectivo, avaliando a segurança e eficácia da reabilitação em uma única etapa, de 26 pacientes com lipoatrofia facial associada ao HIV, tratados com injeções de CaHA. Todos os pacientes apresentaram uma boa tolerância as sessões de reabilitação em uma etapa, sendo relatada uma alta satisfação com os resultados, com estabilidade de 3 meses ao final dos casos. Esses resultados corroboraram com o estudo prospectivo de 12 meses realizado por Carruthers A. e Carruthers J. (2008), ${ }^{46}$ o qual também avaliou a segurança e efetividade do tratamento com CaHA em lipoatrofia facial associada ao HIV, onde todos os 30 pacientes tratados responderam de forma adequada, com resultados satisfatórios e seguros.

Posteriormente em 2009, recebeu aprovação para utilização em mais fins cosméticos. ${ }^{9,30}$ É considerado um produto com capacidade de reparar áreas que necessitam de volume e preenchimento, tendo como principais indicações correção de sulcos moderados a graves na área da face, área nasal, comissura labial, rugas peribucais, malar/ zigomático, contorno mandibular, região temporal, terço médio da face, prega mentoniana, mento e mãos. ${ }^{5,11,26,41}$

Outra indicação é a correção de cicatrizes de acne. Treacy (2013) ${ }^{47}$ comparou a eficácia do uso da CaHA e do ácido hialurônico (AH) no tratamento de 40 pacientes com diferentes graus de atrofia da acne. Após 12 meses do início do tratamento dos indivíduos injetados com CaHA, 22\% dos indivíduos apresentaram uma melhora de $75 \%$, enquanto $48 \%$ mostraram uma melhora de $50 \%$. Isto comparado a uma melhoria média de $0 \%$ para a coorte de ácido hialurônico, onde $85 \%$ do total de pacientes tratados com o HA, apresentaram uma melhora de o a $25 \%$ nas cicatrizes atróficas tratadas aos 12 meses.

\section{Contraindicações e reações adversas}

Embora a CaHA seja ideal para várias áreas da face, existem algumas regiões que são contraindicadas, como a glabela, área periorbicular e lábios. Por possuir uma tendência de moverse facilmente em áreas de extrema mobilidade, é muito comum a formação de nódulos não inflamatórios na região do músculo orbicular da 
boca e músculos orbiculares dos olhos..$^{5,6,11,39,41}$ Além dessas contraindicações, a CaHA também não é indicada para combinações de tratamentos com preenchedores permanentes, como silicone e polimetilmetacrilato. ${ }^{41}$

Por ser um produto biodegradável, não causa reação inflamatória crônica ou imune. ${ }^{5}$ Os eventos adversos mais comuns são leves, hematomas, edema, eritema e dor, os quais são resolvidos espontaneamente em 1 a 5 dias, estando relacionados à injeção..$^{30,39,48}$ Outros efeitos adversos, como formação de nódulos, granulomas, celulite e necrose também foram relatados em casos de tratamento com a CaHA, e assim como em todos os preenchedores dérmicos, grande parte desses eventos adversos podem ser evitados com planejamento e técnica adequada. ${ }^{39}$

Através de uma revisão retrospectiva de 2.089 tratamentos com preenchedores injetáveis de tecidos moles, Daines e Williams (2013) ${ }^{35}$ relataram que a CaHA foi o agente preenchedor mais associado a complicações, cerca de 2,6\% dos casos tratados, com 6 casos de complicações, o que de certa forma, pode ser considerado um índice baixo. Destes, três pacientes $(1,7 \%)$ desenvolveram celulite no local da aplicação, tendo um dos pacientes desenvolvido dois episódios diferentes de celulite na bochecha após sessões com intervalo de 7 meses. Um paciente (o,4\%) desenvolveu um nódulo submucoso visível abaixo da mucosa bucal, e uma paciente (o,4\%) manifestou necrose parcial após a injeção do produto nas pregas melolabiais.

\section{POLICAPROLACTONA}

Assim como o PLLA e a CaHA que são preenchedores cutâneos biodegradáveis e bioestimuladores de colágeno, a policaprolactona (PCL) (Ellansé ${ }^{\circledR}$ ) é um novo estimulador de colágeno biodegradável, introduzido no mercado estético em 2009. ${ }^{11-13,41,49-51}$

\section{Composição e mecanismo de ação}

Esse preenchedor é composto por 30\% de microesferas sintéticas de PCL suspensas em meio aquoso de gel transportador de carboximetilcelulose (CMC) a 70\%. ${ }^{49,50,52,53}$ As microesferas de PCL possuem diâmetro entre 25-50 $\mu \mathrm{m}$, são totalmente esféricas e lisas, com tamanho uniforme, diferindo das partículas de PLLA que possuem uma morfologia rugosa, não uniforme e planas com formato pontiagudo..$^{51,52,54}$

Após a injeção nos tecidos moles, há uma correção imediata no local, assim como ocorre quando injetada a CaHA, no entanto, esse volume é perdido em algumas semanas, quando o gel carreador de CMC é gradualmente reabsorvido por macrófagos, enquanto as microesferas de PCL desempenham a principal característica do produto, a estimulação de novo colágeno, que substitui o volume do transportador reabsorvido em torno das microesferas. ${ }^{41,49,52,53}$

Afim de investigar essa neocolagênese em tecido humano injetado com um preenchedor dérmico à base de policaprolactona, Kim e Abel (2013) ${ }^{49}$ realizaram um estudo piloto com duas pacientes, as quais foram injetadas intradermicamente com o PCL, e após treze semanas foram realizadas análises histológicas através de biópsias, onde confirmou-se a deposição de novo colágeno em torno das partículas de PCL, além da presença de histiócitos.

\section{Características da policaprolactona}

É um preenchedor dérmico biocompatível e bioabsorvível, que tem sido estudado e bem documentado desde 1980. ${ }^{55,56}$ As cadeias de PCL são divididas através da hidrólise das ligações ésteres, resultando em ácido hidroxicapróico e água, que são reabsorvidos por vias metabólicas e rapidamente excretados através da urina e fezes. ${ }^{56}$

Com relação a sua durabilidade, comercialmente existem 4 versões de preenchimento dérmico à base de PCL: Ellansé-S ${ }^{\circledR}$, Ellansé-M ${ }^{\circledR}$, Ellansé-L ${ }^{\circledR}$, Ellansé-E ${ }^{\circledR}$; com longevidade esperada de 1, 2, 3 e 4 
anos, respectivamente. ${ }^{49,52,57} \mathrm{~A}$ única característica diferente entre as versões, que resulta na diferença de longevidade dos produtos, é o comprimento médio inicial das cadeias poliméricas individuais nas microesferas e o número de ligações éster, que aumentam em cada um dos produtos, e que se dividem progressivamente até o tamanho final de degradação. Somente nesse momento que as microesferas colapsam, perdendo o efeito de andaime e, portanto, o volume ligado à neocolagênese..$^{50,52,56}$

Com o objetivo de demonstrar a eficácia, segurança e longevidade de duas versões da PCL (versão S x versão M), Moers-Carpi e Sherwood (2013) $)^{2}$ realizaram um ensaio clínico prospectivo, randomizado e controlado de 24 meses, em 40 pacientes tratados para correção de pregas nasolabiais. Os resultados do estudo mostraram que aos 12 meses ambas versões mostraram bons resultados, com melhora sustentada em 90\% e 91,4\%, PCL-S e PCL-M respectivamente. Aos 24 meses, o PCL-M mostrou-se mais eficaz que o PCL-S, com melhora sustentada até o período de 2 anos do estudo, confirmando que a versão PCL-M possui resultados mais duradouros que o PCL-S.

\section{Diretrizes gerais do produto}

Há quatro versões disponíveis no mercado estético, que são comercializadas em seringas estéreis de $1,0 \mathrm{ml}$ prontas para uso. ${ }^{52}$ Afim de gerenciar a dor e o desconforto durante o tratamento, alguns autores recomendam a mistura da lidocaína a $2 \%$ ao preenchedor dérmico à base de PCL, evitando-se a necessidade de realizar bloqueios nervosos ou infiltração local, reduzindo assim o tempo de tratamento e evitando a distorção do tecido que pode ser causada pela injeção de anestésicos locais. ${ }^{58}$

Interessados em investigar os efeitos nas propriedades físicas da carga dérmica à base de PCL após a mistura com lidocaína, De Melo e colaboradores (2012) $5^{58}$ afirmaram que a mistura de lidocaína no preenchimento dérmico à base de PCL pode ser realizada com segurança, sem alterações prejudiciais as propriedades físicas do preenchimento dérmico original. Além disso, recomenda-se um máximo de $0.2 \mathrm{ml}$ de lidocaína misturada com $1 \mathrm{ml}$ do preenchedor dérmico, devendo ser feito pelo menos de 15 a 20 movimentos de mixagem, com conector Luer Lock.

Os planos de aplicação do produto são de duas naturezas, ou deve ser injetado no plano subcutâneo, ou mais profundo, no plano supraperiosteal..$^{50,59}$ Recomenda-se aplicar pequenas quantidades, sendo desejável a subcorreção para permitir tempo para o processo de neocolagênese ter efeito. Além disso, deve-se esperar no mínimo 3 meses após o tratamento inicial para realizar uma revisão do paciente e, caso necessário, realizar uma aplicação adicional..$^{0}$

\section{Principais indicações}

No início de 2009, a família dos prenchedores dérmicos à base de PCL recebeu marcação CE (Conformidade Europeia) para implante dérmico e subdérmico profundo para correção de rugas e dobras, logo em seguida, foi introduzido no mercado estético europeu. ${ }^{52,59}$ Desde então, foi disponibilizado em mais de 80 países. ${ }^{59}$

A policaprolactona possui a capacidade de reparar áreas que necessitam de volume e preenchimento. Alguns estudos verificaram a eficácia e segurança do preenchedor de PCL na correção de pregas nasolabiais, no aumento da testa, e no rejuvenescimento das mãos, tendo todos apresentado resultados eficazes e seguros, sem relato de alguma complicação grave. ${ }^{51-53,57}$

Através de um relato de caso, Lin (2018) ${ }^{60}$ descreveu uma restauração do volume facial usando a policaprolactona em uma mulher asiática de 46 anos de idade. $\mathrm{O}$ tratamento foi realizado em várias áreas da face superior, média e inferior, com o objetivo de corrigir defeitos descendentes de gordura e contorno causados pela perda de volume nos compartimentos 
profundos de gordura e na plataforma craniofacial. Após 12 semanas de acompanhamento, foi feita uma análise do antes e depois do tratamento usando o sistema de imagem $3 \mathrm{D}$, sendo verificada melhora altamente significante do volume facial em várias camadas de tecido da face.

\section{Contraindicações e efeittos adversos}

Embora a PCL seja uma opção de tratamento para várias áreas da face, existem algumas regiões que são contraindicadas, como na região periorbital (pálpebras, olheiras, "pés de galinha”), glabela, devido risco de eventos isquêmicos oculares que podem levar à perda da visão, e lábios. Também são contraindicados pacientes com alergias graves manifestadas por histórico de anafilaxia; doença cutânea aguda ou crônica (infecção ou inflamação); pacientes suscetíveis à formação de quelóides ou cicatrizes hipertróficas; pacientes usuários de cortisona, devido possibilidade de inibição do crescimento do tecido conjuntivo; e pacientes tratados anteriormente com preenchedores permanentes. ${ }^{5}$

Desde que recebeu a licença de comercialização, um sistema de farmacovigilância foi criado para registrar efeitos adversos (EA) em todo o mundo. Mais de 490.00o seringas foram utilizadas desde o lançamento em 2009 até dezembro de 2016, e a taxa de EA é baixa, em 0,049\% (um evento por seringa), indicando que o estimulador à base de PCL é bem tolerado. ${ }^{5}$

Em seus estudos acerca de eventos adversos, De Melo e colaboradores (2017), ${ }^{59}$ Bae (2016), ${ }^{57}$ e Kim e Abel (2014), ${ }^{49}$ relataram que os mais comuns são leves, e estão relacionados ao próprio procedimento de injeção, como edema e equimose que desaparecem de forma espontânea após alguns dia, não tendo nenhum dos autores relatado eventos adversos graves, sendo estes geralmente relacionados a erros técnicos, como injeção superficial ou injeção em bolus, ou seja, diretamente na circulação sistêmica do paciente. No entanto, em 2018, Skrzypek e colaboradores ${ }^{61}$ relataram o primeiro caso de granuloma como complicação da injeção cutânea dérmica com o preenchedor à base de policaprolactona. $\mathrm{O}$ caso relatado aconteceu em mulher de 68 anos de idade, que foi injetada com PCL- M na região das dobras nasolabiais, após 1 ano da aplicação a paciente observou pequenos nódulos com descoloração azulada da pele adjacente, presentes bilateralmente nos locais da injeção. Inicialmente foi feito um exame clínico, em seguida uma ultrassonografia de alta frequência (HFU) da pele, e posteriormente uma biópsia incisional, a qual foi submetida a análise imuno-histoquímica, apresentando como diagnóstico histopatológico granuloma de corpo estranho.

\section{POLIMETILMETACRILATO}

O polimetilmetacrilato (PMMA) é um polímero utilizado na prática médica desde 1945, comumente como cimento ósseo. ${ }^{6}$ Como bioestimulador de colágeno foi desenvolvido na Alemanha há mais de 20 anos, comercialmente (ArtePlast) ${ }^{\circledR}$, substituído pelo seu sucessor de segunda geração, o (Artecoll) ${ }^{\circledR}$, os quais foram retirados do mercado devido uma altíssima taxa de formação de granuloma, que foram sugeridos ao fato das microesferas de PMMA possuírem um diâmetro menor que $20 \mu \mathrm{m}$, que provocavam uma resposta de corpo estranho, sendo assim reprovados pelo FDA. Hoje, sua terceira geração alterada é comercialmente chamada de $\left(\right.$ ArteFill) ${ }^{\circledR} .9,13,26,62$

\section{Composição e mecanismo de ação}

O bioestimulador à base de PMMA de terceira geração é composto de microesferas sintéticas de polimetilmetacrilato com diâmetro de 30-50 $\mu \mathrm{m}$, existindo aproximadamente 6 milhões de microsesferas a cada mililitro do produto, as quais são suspensas em gel carreador, que pode ser à base de colágeno bovino, carboximetilcelulose 
ou hialuronato de sódio. ${ }^{9,11,26}$ Diferentemente dos outros produtos bioestimuladores de colágeno, faz-se necessário realizar um teste cutâneo prétratamento, quando o gel transportador utilizado é à base de colágeno bovino, com o intuito de minimizar o risco de reações de hipersensibilidade. , $^{6,11,30,34,62}$

Assim como o ácido poli-L-láctico, a hidroxiapatita de cálcio e a policaprolactona que estimulam a neocolagênese, o polimetilmetacrilato também possui essa capacidade de formar novo colágeno, através de processo inflamatório. ${ }^{6,63}$ Após ser injetado nos tecidos, o transportador é degradado pelo organismo cerca de 1 a 3 meses e, em seguida, o novo colágeno é depositado pelo hospedeiro, o qual envolve as microesferas de PMMA que funcionam como andaime. ${ }^{11,26,64} \mathrm{O}$ aumento de volume resultante do preenchedor consiste em 20\% de PMMA e 80\% de tecido conjuntivo autólogo. ${ }^{26,30}$

\section{Características do polimetillmetacrilato}

O PMMA de terceira geração é considerado um produto biocompatível, devido as características morfológicas das microesferas, que são uniformes, redondas e lisas, e especialmente pela ausência de partículas com menos de $20 \mu \mathrm{m}$ de diâmetro. Esses pontos chaves para a biocompatibilidade na pele humana foram demonstrados em experiências com animais, realizadas por Lemperle e colaboradores (2004) ${ }^{64}$

Uma diferença entre o PMMA e os outros produtos, está relacionada à durabilidade, enquanto o PLLA, CaHA e PCL são bioestimuladores semipermanentes e biodegradáveis, o PMMA é classificado como permanente e não biodegradável, em razão do tamanho, lisura de superficie e uniformidade das microesferas que impedem sua fagocitose pelos macrófagos, além de limitar a migração do produto. . $34,41,56,63$

Através de um relatório, Cohen e colaboradores $(2006)^{65}$ resumiram o ensaio clínico realizado pela FDA, comparando a segurança e eficácia das injeções de policaprolactona com as injeções de colágeno, e avaliação do progresso dos resultados de 4 a 5 anos. Dos 111 indivíduos tratados com com o PMMA, 69 retornaram para um acompanhamento entre 4 e 5 anos, sendo avaliados clinicamente e através de fotografias, onde as melhorias resultantes do PMMA foram consideradas estáveis, pelo menos até o tempo de duração do estudo.

\section{Diretrizes gerais do produto}

No Brasil, existem duas marcas que possuem o registro da ANVISA, (Linnea Safe) ${ }^{\circledR}$ e (Biossimetric) ${ }^{\circledR}$, os quais são comercializados em diferentes concentrações de polimetilmetacrilato, em seringas plásticas de 1,0 mL ou 3,0 mL prontas pra uso. ${ }^{38}$

É de extrema importância localizar o plano correto para injeção do PMMA. ${ }^{62} \mathrm{O}$ produto deve ser aplicado nos planos profundos, na junção dérmica-subcutânea. ${ }^{6,26,30,62}$ A quantidade adequada do produto e número de sessões, varia conforme as características cutâneas, ósteo-cartilaginosas e musculares do paciente, quais as áreas tratadas, e do objetivo do tratamento. Por ser um produto definitivo e o aumento progressivo do volume, é recomendado evitar-se a correção excessiva, sempre realizando com cautela. Nos casos que os retoques são necessários, é aconselhável respeitar um intervalo de 6 semanas entre as sessões. ${ }^{34,66}$

\section{Principais indicações}

Recebeu aprovação da FDA em 2006 como o primeiro preenchedor permanente para injeção nas dobras nasolabiais. ${ }^{26,62,63}$ De forma off label é utilizado em rugas profundas, cicatrizes de acne e cicatrizes traumáticas, defeitos dérmicos de tecidos moles e ósseos e rejuvenescimento das mãos. ${ }^{26,67}$

Baseados em suas experiências clínicas ao longo de 15 anos, Lemperle e colaboradores (2010) ${ }^{63}$ realizaram um resumo de indicações e aplicações do preenchedor à base de PMMA para aumento de tecidos moles. Os autores relataram utilização na 
área das dobras nasolabiais, área periocular lateral, linhas horizontais da testa, pálpebras inferiores, cicatrizes de acne, irregularidades do nariz, preenchimento labial e rejuvenescimento das mãos. Os resultados foram considerados satisfatórios, não sendo relatada nenhuma complicação grave, havendo apenas alguns efeitos colaterais menores como nódulos na área dos lábios e na dobra nasolabial, os quais foram relacionados à técnica.

Posteriormente, foi aprovado pela FDA para correção de lipoatrofia facial associada ao HIV, sendo relatados na literatura casos com resultados satisfatórios. ${ }^{5,26}$ Podemos observar esses resultados no estudo realizado por Dornelas et al $(2013)^{68}$, onde 41 pacientes apresentando lipoatrofia facial associada com HIV/AIDS, foram submetidos a bioplastia com o PMMA, tendo todos os pacientes apresentado melhoras favoráveis esteticamente.

\section{Contraindicações e efeitos adversos}

Embora existam relatos do uso do PMMA na região dos lábios e área dos olhos, muitos autores não recomendam sua injeção nesses locais, devido grande risco de formação de nódulos, possivelmente devido ação do músculo orbicular da boca que pode mover o material.9.34,63

Ao usar um preenchedor espera-se uma resposta granulomatosa pequena, tendo como efeitos colaterais mais comuns, o sangramento, hematomas, eritema e edema, relacionados à injeção, e que também são frequentes nos bioestimuladores. ${ }^{34}$ No entanto, existem alguns relatos de complicações tardias mais graves relacionadas ao tratamento com o PMMA, em razão dos resultados duradouros, havendo uma chance maior de exacerbação de uma inflamação crônica pré-existente. $5,69,70$

Em 2017, Ibrahim e Dover ${ }^{71}$ relataram um caso de nódulo tardio, em mulher de 55 anos, após infecção respiratória superior leve, tendo relatado preenchimento com o PMMA 7 anos antes na área das dobras nasolabiais e bochechas. A paciente apresentou edema facial generalizado com endurecimento sólido das dobras nasolabiais, do nariz médio e das comissuras orais, além de nódulos firmes, pequenos e palpáveis, sendo relatado sensação de extrema pressão sobre a face média. Em biópsia, foi encontrado infiltrado inflamatório crônico dentro do subcutâneo, composto por macrófagos e células gigantes de corpo estranho, o qual foi tratado com altas doses de corticoides intralesionais, havendo completa resolução. Outro caso de exacerbação de uma inflamação crônica pré-existente, foi relatado por Bringel e colaboradores (2012),,$^{72}$ onde uma paciente portadora de hepatite $\mathrm{C}$ a qual estava em tratamento com Interferon, que devido sua capacidade imunoestimuladora causou o aparecimento de edema facial e granulomas nos sulcos nasogenianos bilateralmente e na glabela, tendo a paciente relatado realização de preenchimento com PMMA 5 anos antes, nas áreas afetadas. Desse modo, é recomendada uma avaliação sorológica previamente ao uso de preenchedores permanentes, a fim de evitar exarcebações granulomatosas.

\section{DISCUSSÃO}

Os bioestimuladores de colágeno são uma ótima opção no tratamento para o rejuvenescimento facial, visto sua capacidade de estimular a formação de um novo colágeno através de processo inflamatório local. Esse mecanismo de ação foi investigado por Goldberg e colaboradores (2013), ${ }^{25}$ Yutskovska, Kogan e Leshunov (2014), ${ }^{43}$ e Kim e Abel (2013), ${ }^{49}$ tendo todos confirmado essa resposta tecidual humana.

Quanto ao início do efeito volumizador, existe uma diferença entre as substâncias. O PLLA não possui um efeito imediato, já a CaHA, PCL e PMMA assim que injetados provocam uma correção imediata, tendo a dissipação do seu gel carreador de forma mais lenta que no PLLA, mas todos tem seu efeito alcançado de forma progressiva e gradual. 
Com isso, é importante informar ao paciente que os resultados são visíveis com o passar do tempo.

Há uma grande diferença entre os produtos com relação à longevidade dos efeitos. A hidroxiapatita de cálcio, policaprolactona e o ácido poli-L-láctico são considerados biodegradáveis e semipermanentes, tendo a CaHA o menor tempo de duração quando comparada ao PLLA e PCL, em média de 12 a 18 meses, podendo chegar até 24 meses. Já o ácido poli-L-láctico apresenta efeitos mais duráveis, de até 4 anos sem necessidade de retoques, conforme o estudo de Rendon (2012). ${ }^{21}$ A policaprolactona diferentemente dos outros dois bioestimuladores semipermanentes, possui no mercado quatro versões que apresentam diferentes longevidades de 1 até 4 anos, sendo um ponto positivo, pois o paciente tem a opção de escolher a versão que deseja, e consequentemente o tempo de efeito do produto. No entanto, a duração dos efeitos pode variar devido a fatores específicos de cada paciente, que precisam ser estudados em cada caso. $O$ polimetilmetacrilato como um bioestimulador não biodegradável e permanente, apresentou no estudo de Cohen e colaboradores (2006), ${ }^{65}$ resultados estáveis em 5 anos referente ao tempo de duração da investigação, sendo importante o acompanhamento mais longo dos pacientes tratados com o PMMA, com o intuito de verificar sua estabilidade.

A principal indicação dos produtos é melhorar o aspecto da pele, agindo nas camadas mais profundas, além de devolver os volumes e contornos faciais perdidos, de forma sutil e com aspecto natural, através da bioestimulação de um novo colágeno, por isso os produtos não são aplicados diretamente nas rugas, sulcos ou linhas, e sim nas áreas côncavas e com sombras que perderam gordura, buscando um tratamento tridimensional, atuando na perda de volume. Todos os quatro produtos apresentam relatos de resultados favoráveis nos tratamentos cosméticos da face. No tratamento de pacientes com cicatrizes de acne, Sadiki e Palmisano (2009), ,2 em seu estudo com o PLLA, relataram resultados favoráveis; o que também foi relatado nos estudos realizados por Daines e Williams (2013) ${ }^{35}$ com a CaHA, e Lemperle e colaboradores (2010) ${ }^{63}$ com o PMMA. Diante disso, os resultados em pacientes com cicatrizes de acne tratados com PLLA, CaHA e PMMA são satisfatórios, no entanto, não foram encontrados relatos de pacientes tratados com a PCL nesses casos. Com relação ao uso dos produtos no tratamento de pacientes com lipoatrofia facial associada ao HIV, os estudos de Rauso et al (2013)45 e Carruthers A. e Carruthers J. (2008) ${ }^{46}$ utilizando a CaHA demonstraram resultados altamente satisfatórios, assim também como nos estudos de Bassichis et al. (2012) ${ }^{31}$ e Dornelas et al (2013) ${ }^{68} \mathrm{com}$ o PLLA e PMMA, respectivamente. Novamente não foram encontrados estudos relacionados a PCL no tratamento nesses tipos de casos.

Alguns pontos foram apontados como sendo muito importantes para alcançar o sucesso do tratamento. A maioria dos produtos são comercializados em seringas prontas para uso, sendo necessário apenas fazer uma correta homogeneização, mas é comum a mistura do produto com anestésicos locais, a fim de diminuir o desconforto do paciente e distorções locais provocadas pela aplicação prévia do anestésico. No entanto, o PLLA é o único produto que necessita de uma reconstituição entre 6 e $8 \mathrm{~mL}$ com água destilada e lidocaína a $2 \%$, e tempo de repouso de 24 a 72 horas antes da aplicação, segundo Rendon (2012), ${ }^{21}$ sendo um ponto crucial para evitar a formação de nódulos e obstrução de agulhas/ cânulas. É de extrema importância o cuidado nessas manipulações para diminuir o máximo possível a chance de contaminação dos produtos. Outro ponto crítico é a aplicação no plano correto, além de saber individualizar a quantidade de produto usado e o número de sessões necessárias, seguindo sempre a 
regra de tratar, esperar e avaliar, diminuindo assim os riscos de efeitos adversos.

Embora os bioestimuladores de colágeno sejam uma ótima opção para o tratamento de várias áreas da face, os estudos mostraram que algumas áreas são mais propensas a efeitos adversos no local da injeção, sendo contraindicadas as regiões periorbicular, periorbital, lábios e glabela, devido grande ação muscular, sendo comum formação de nódulos. Além disso, não é recomendada a combinação de bioestimuladores permanentes (PMMA) ou silicone com qualquer outro bioestimulador, por haver grande risco de formação de granulomas, comprovado por Rendon (2012). ${ }^{21}$

Assim como os preenchedores dérmicos, todos os produtos bioestimuladores de colágeno são bem tolerados, no entanto, é comum após a aplicação o desconforto, hematomas, eritema ou edemas locais, leves e transitórios, com resolução espontânea. As complicações sistêmicas são mais raras. No estudo de Daines e Williams (2013) ${ }^{35}$ com o PLLA e a CaHA foi apresentado um baixo índice de eventos adversos, sendo relatados nódulos não inflamatórios, pápulas, granulomas, celulite e necrose. A policaprolactona até 2018 não apresentava nenhum relato de efeitos adversos além dos mais comuns e leves relacionados à injeção, tendo seu primeiro caso relatado de granuloma no estudo de Srzypek e colaboradores (2018). ${ }^{61}$ Acreditase que estes estejam relacionados a considerações técnicas, que podem ser evitados com planejamento e técnicas adequadas. Em contrapartida, o PMMA é o produto que apresenta mais relatos de complicações tardias graves relacionadas ao tratamento, como mostrado no estudo de Ibrahim e Dover (2017), ${ }^{71}$ tendo como razão a longevidade do produto, havendo uma chance maior de exacerbação de inflamações crônicas pré-existentes.

\section{CONCLUSÃO}

Os preenchedores dérmicos bioestimuladores são excelentes materiais com capacidade de prevenir ou reverter os efeitos do processo de envelhecimento facial, devido à capacidade preenchedora e bioestimuladora de novo colágeno que possuem.

Além disso, é notável que todos os preenchimentos dérmicos bioestimuladores descritos podem causar efeitos adversos precoces, tardios ou retardados. Em particular, o polimetilmetacrilato, preenchedor permanente, é o que apresenta maior quantidade de efeitos adversos, em razão da sua alta longevidade, levando a exacerbação de inflamações crônicas préexistentes. Com isso, é importante cientizar o paciente acerca dos riscos e benefício da sua utilização, devendo assim, o profissional usá-lo com cautela e acompanhar de forma contínua seus pacientes.

Concluímos que ainda não há um preenchedor bioestimulador considerado perfeito, mas excelentes opções com características únicas, que devem ser escolhidos de acordo com a individualidade de cada paciente, levando em consideração o local de tratamento, a experiência do profissional com o produto, a expectativa do paciente com relação aos resultados, tempo para obtenção do resultado, e outras variáveis.

\section{AGRADECIMENTOS}

À professora Dra. Marília de Lima Soares, por todo apoio e ensinamento, e à minha família por toda compreensão e incentivo.

\section{REFERÊNCIAS BIBLIOGRÁFICAS}

1. Papazian MF, Silva LM, Crepaldi AA, Crepaldi MLS, Aguiar AP. Principais aspectos dos preenchedores faciais. Revista Faipe. 2018;8(1):101-16.

2. Conselho Federal de Odontologia (BR). Resolução n ${ }^{0} 198$, de 29 de janeiro de 2019. Reconhece a Harmonização Orofacial como especialidade odontológica, e dá outras providências. Diário Oficial da União [Internet]. 2019 Jan 31 [cited 2020 May 5];22:91. Disponível em: https://bit.ly/3foEVeD

3. Coimbra DD, Uribe NC, Oliveira BS. "Quadralização facial" no processo do envelhecimento. Surg Cosmet Dermatol. 2014;6(1):6571. 
4. Franzen JM, Santos JMSR, Zancanaro V. Colágeno: uma abordagem para a estética. RIES. 2013 Sept;2(2):49-61. doi: 10.33362/ries.v2i2.161.

5. Miranda LHS. Ácido poli-L-lático e hidroxiapatita de cálcio: melhores indicações. In: Lyon S, Silva RC. Dermatologia estética: medicina e cirurgia estética. Rio de Janeiro: MedBook; 2015. p. $267-80$

6. Monteiro EO, Parada MOB. Preenchimentos faciais - parte um. Rev Bras Med. 2010 jul;67(Suppl 4):6-4.

7. Sharabi SE, Hatef DA, Koshy JC. Mechanotransduction: the missing link in the facial aging puzzle? Aesth Plast Surg. 2010;34(5):603-11. doi: 10.1007/s00266-010-9519-5.

8. Fitzgerald R, Vleggaar D. Facial volume restoration of the aging face with poly-L-lactic aciddth. Dermatol Ther. 2011 Jan-Feb;24:2-27. doi: 10.1111/j.1529-8019.2010.01375.x.

9. Attenello $\mathrm{NH}$, Maas CS. Injectable fillers: review of material and properties. Facial Plast Surg. 2015;31:29-34. doi: 10.1055/s-0035-1544924.

10. Avelar LE, Cazerta CE. The improvement of the skin quality with the use of PLLA. J Dermat Cosmetol. 2018;2(2):101-2. doi: 10.15406/jdc.2018.02.00052.

11. Flores IC, González JLM. Materiales de relleno en dermatología. Dermatología CMQ. 2011 Oct;9(4):275-83.

12. Lam SM, Azizzadeh B, Graivier M. Injectable poly-L-lactic acid (sculptra): technical considerations in soft-tissue contouring. Plast Reconstr Surg. 2006;118(3 Suppl.):55S-63S. doi: 10.1097/o1.prs.0000234612.20611.5a.

13. Bentkover SH. The biology of facial fillers. Facial Plast Surg. 2009;25(2):73-85. doi: 10.1055/s-0029-1220646

14. Tagle JM, Macchetto PC, Páramo RMD. Clinical performance of a dermal filler containing natural glycolic acid and a polylactic acid polymer. J Clin Aesthetic Dermatol. 2010 Feb;3(2):42-7.

15. Beer K. Dermal fillers and combinations of fillers for facial rejuvenation. Dermatol Clin. 2009 Oct;27(4):427-32. doi: 10.1016/j.det.2009.08.011.

16. Lacombe V. Sculptra: a stimulatory filler. Facial Plast Surg. 2009;25(2):95-99. doi: 10.1055/s-0029-1220648

17. Fabi SG, Goldman MP. The safety and efficacy of combining poly-L-lactic acid with intense pulsed light in facial rejuvenation: a retrospective study of 90 patients. Dermatol Surg. 2012;38:1208-16. doi: 10.1111/j.1524-4725.2012.02476.x

18. Schierle CF, Casas LA. Nonsurgical rejuvenation of the aging face with injectable poly-L-lactic acid for restoration of soft tissue volume. Aesthet Surg J. 2011 Jan;31(1):95-109. doi: 10.1177/1090820X10391213.
19. Satini RM, Silva F, Cardoso GF. Uso do ácido poli-L-láctico como restaurador de volume facial. Rev Bras Cir Plást. 2013;28(2):223-6.

20. Sherman RN. Sculptra: the New Three-Dimensional Filler. Clin Plastic Surg. 2006;33(4):539-50. doi: 10.1016/j. cps.2006.09.001.

21. Rendon MI. Long-term aesthetic outcomes with injectable poly-L-lactic acid: observations and practical recommendations based on clinical experience over 5 years. J Cosmet Dermatol. 2012;11,93-100.

22. Williams DF. On the mechanisms of biocompatibility. Biomaterials. 2008;29(20):2941-53. doi:10.1016/ j.biomaterials.2008.04.023.

23. Machado Filho CDS, Santos TC, Rodrigues APLJM, Cunha MG. PolyLlactic acid: a biostimulating agent. Surg Cosmet Dermatol. 2013;5(4):34550.

24. Narins RS. Minimizing Adverse Events Associated with poly-L-lactic acid injection. Dermatol Surg. 2008;34(S1):S100-4. doi: 10.1111/j.1524-4725.2008.34250.x.

25. Goldberg D, Guana A, Volk A, Daro-Kaftan E. Single-arm study for the characterization of human tissue response to injectable poly-L-lactic acid. Dermatol Surg. 2013;39(6):91522. doi: 10.1111/dsu.12164

26. Donis AA, Gutiérrez PG, Domínguez NR, Moreno GS, Ávila JR. Revisión de materiales de relleno. Dermatología CMQ. 2015;13(1):54-64.

27. Haddad A, Kadunc BV, Guarnieri C, Noviello JS, Cunha MG, Parada MB. Conceitos atuais no uso do ácido poli-L-láctico para rejuvenescimento facial: revisão e aspectos práticos. Surg Cosmet Dermatol. 2017;9(1):60-71. doi: 10.5935/ scd1984-8773.201791952

28. Dermik Laboratories (US) .Sculptra [bula]. Bridgewater; 2009. 29. Mitchel P, Goldman MP. Cosmetic use of poly-L-lactic acid: my technique for success and minimizing complications. Dermatol Surg. 2011;37(5):688-93. doi: 10.1111/j.1524-4725.2011.01975.x 30. Greco TM, Antunes MB, Yellin SA. Injectable fillers for volume replacement in the aging face. Facial Plast Surg. 2012;28:8-20. doi: 10.1055/s-0032-1305786

31. Bassichis B, Blick G, Cnant M, Condoluci D, Echavez M, Eviatar $\mathrm{J}$, et al. Injectable poly-L-lactic acid for human immunodeficiency virus-associated facial lipoatrophy: cumulative year 2 interim analysis of an open-label study (FACES). Dermatol Surg. 2012;38(7 Pt 2):1193-205. doi: 10.1111/j.1524-4725.2012.02474.x 32. Sadick NS, Palmisano L. Case study involving use of injectable poly-L-lactic acid (PLLA) for acne scars. J Der- 
matolog Treat. 2009;20(5):302-7. doi: https://doi.org/ 10.1080/09546630902817879.

33. Requena L, Requena C, Christensen L, Zimmermann US, Kutzner H, Cerroni L. Adverse reactions to injectable soft tissue fillers. J Am Acad Dermatol. 2011;64(1):1-34. doi: https://doi.org/10.1016/j.jaad.2010.02.064

34. Alam M, Gladstone H, Krame EM, Murphy JP, Nouri K, Neuhaus IM, et al. Guidelines of care: injectable fillers. Dermatol Surg. 2008;34(Suppl 1):S115-48. doi: https://doi. org/10.1111/j.1524-4725.2008.34253.x.

35. Daines SM, Williams EF. Complications associated with injectable soft-tissue fillers. JAMA Facial Plast Surg. 2013;15(3):22631. doi: https://doi.org/10.1001/jamafacial.2013.798.

36. Beer K, Avelar R. Relationship between delayed reactions to dermal fillers and biofilms: facts and considerations. Dermatol Surg. 2014;40:1175-9 doi: https://doi.org/10.1097/01. DSS.0000452646.76270.53.

37. Lemperle G, Gauthier-Hazar N, Wolters M, Eisemann-Klein M, Zimmermann U, Duffy DM. Foreign body granulomas after all injectable dermal fillers: part 1. possible causes. Plast Reconstr Surg. 2009;123(6):1842-63. doi: https://doi. org/10.1097/PRS.obo13e31818236d7.

38. Agência Nacional de Vigilância Sanitária (BR). Consulta de produtos para saúde [Internet]. Brasília, DF; 2019 [cited 2019 Oct 25]. Disponível em: https://consultas.anvisa.gov.br.

39. Loghem JV, Yutskovskaya YA, Werschler P. Calcium hydroxylapatite: over a decade of clinical experience. J Clin Aesthet Dermatol. 2015;8(1):38-49.

40. Goldie K, Peeters W, Alghoul M, Butterwick K, Casabona G, Chao YYY, et al. Global consensus guidelines for the injection of diluted and hyperdiluted calcium hydroxylapatite for skin tightening. Dermatol Surg. 2018;44(Suppl 1):S32-41. doi: https://doi.org/10.1097/DSS.oooooooooooo1685.

41. Jacovella PF. Use of calcium hydroxylapatite (Radiesse $®$ ) for facial augmentation. Clin Interv Aging. 2008;3(1):161-74.

42. Berlin AL, Hussain M, Goldberg DJ. Calcium hydroxylapatite filler for facial rejuvenation: a histologic and immunohistochemical analysis. Dermatol Surg. 2008;34(Suppl 1):S64-7. doi: https://doi.org/10.1111/j.1524-4725.2008.34245.x.

43. Yutskovskay Y, Kogan E, Leshunov E. A randomized, split-face, histomorphologic study comparing a volumetric calcium hydroxylapatite and a hyaluronic acid-based dermal filler. J Drugs Dermatol. 2014;13(9):47-52.

44. Sundaram H, Voigts B, Beer K, Meland M. Comparison of the rheological properties of viscosity and elasticity in two categories of soft tissue fillers: calcium hydroxylapatite and hyaluronic acid. Dermatol Surg. 2010 Nov;36(Suppl 3):185965. doi: https://doi.org/10.1111/j.1524-4725.2010.01743.x

45. Rauso R, Curinga G, Rusciani A, Colella G, Amore R, Tartaro G. safety and efficacy of one-step rehabilitation of human immunodeficiency virus-related facial lipoatrophy using an injectable calcium hydroxylapatite dermal filler. Dermatol Surg. 2013;39(12):1887-94. doi: https://doi.org/10.1111/dsu.12358

46. Carruthers A, Carruthers J. evaluation of injectable calcium hydroxylapatite for the treatment of faciallipoatrophy associated with human immunodeficiency virus. Dermatol Surg. 2008;34(11):148699. doi: https://doi.org/10.1111/j.1524-4725.2008.34323.x

47. Treacy P. J. Dermall filler treatment for atrofic acne scarring. Prime [Internet]. 2013 Mar [cited 2019 Oct 25]. Disponível em: https://www.linkedin.com/pulse/calcium-hydroxylapatite-treatment-acne-scarring-dr-patrick-j-treacy/

48. Dadzie OE, Mahalingam M, Parada M, El Helou T, Philips T, Bhawan J. Adverse cutaneous reactions to soft tissue fillers - a review of the histological features.JCutan Pathol. 2008;35(6):53648. doi: https://doi.org/10.1111/j.1600-0560.2007.00853.x

49. Kim JA, Abel DV. Neocollagenesis in human tissue injected with a polycaprolactone-based dermal filler. J Cosmet Laser Ther. 2015;17(2):99-101. doi: 10.3109/14764172.2014.968586

50. Goodwin P. Collagen stimulation with a range of polycaprolactone dermal fillers. JAN. 2018 Out;7(Suppl 2):22-8. doi: https://doi.org/10.12968/joan.2018.7.Sup2.22

51. Galadari H, Abel D, Nuami KA, Faresi FA, Galadari I. A randomized, prospective, blinded, split-face, single-center study comparing polycaprolactone to hyaluronic acid for treatment of nasolabial folds. J Cosmet Dermatol. 2015 Mar;14(1):27-32. doi: https://doi.org/10.1111/jocd.12126

52. Moers-Carpi MM, Sherwood S. Polycaprolactone for the correction of nasolabial folds: a 24-month, prospective, randomized, controlled clinical trial. Dermatol Surg. 2013;39(3):457-63. doi: https://doi.org/10.1111/dsu.12054

53. Figueiredo VM.Afive-patient prospective pilot study of a polycaprolactone based dermal filler for hand rejuvenation. JCosmet Dermatol. 2013 Mar;12(1):73-7. doi: https://doi.org/ 10.1111/jocd.12020 54. Kwon T, Han SW, Yeo IK, Kim JH, Kim JM, Hong JY, et al. Biostimulatory effects of polydioxanone, poly-zd, l lactic acid, and polycaprolactone fillers in mouse model. J Cosmet Dermatol. 2019;18(4):1002-8. doi: https://doi.org/10.1111/jocd.12950

55. Pitt CG, Chasalow FI, Hibionada YM, Klimas DM, Schindler A. Aliphatic polyesters. I. The degradation of poly (e-caprolactone) in vivo. J Ap Pol Science. 1981;26(11):3779-87. doi: https://doi.org/10.1002/app.1981.070261124 
56. Sun H, Mei L, Song C, Cui X, Wang P. The in vivo degradation, absorption and excretion of PCL-based implant. Biomaterials. 2006;27:1735-40. doi: https://doi.org/10.1016/j. biomaterials.2005.09.019

57. Bae B, Lee G, Oh S, Hong K. Safety and long-term efficacy of forehead contouring with a polycaprolactone-based dermal filler. Dermatol Surg. 2016;42(11):1256-6o. doi: https://doi. org/10.1097/DSS.0oooooooooooo913

58. Melo F, Marijnissen-Hofste J. Investigation of physical properties of a polycaprolactone dermal filler when mixed with lidocaine and lidocaine/epinephrine. Dermatol Ther. 2012;2:1-13. doi: https://doi.org/10.1007/s13555-012-0013-7

59. Melo F, Nicolau P, Piovano L, Lin S, Baptista-Fernandes T, King MI, et al. Recommendations for volume augmentation and rejuvenation of the face and hands with the new generation polycaprolactone-based collagen stimulator (Ellansé $®)$. Clin Cosmet Investig Dermatol. 2017;8(10):431-40. doi: https://doi.org/10.2147/CCID.S145195

6o. Lin SL. Polycaprolactone facial volume restoration of a 46-year-old Asian women: A case report. J Cosmet Dermatol. 2018;17(3):328-32. doi: https://doi.org/10.1111/jocd.12482

61. Skrzypek E, Górnicka B, Skrzypek DM, Krzysztof MR. Granuloma as a complication of polycaprolactone-based dermal filler injection: ultrasound and histopathology studies, Journal of Cosmetic and Laser Therapy. J Cosmet Laser Ther. 2019;21(2):65-8. doi: https://doi.org/10.1080/14764172.2018.1461229

62. Lemperle G, Knapp TR, Sadick NS, Lemperle SM. ArteFill permanent injectable for soft tissue augmentation: I. Mechanism of action and injection techniques. Aesth Plast Surg. 2010;34:26472. doi: https://doi.org/10.1007/soo266-0o9-9413-1

63. Lemperle G, Sadick NS, Knapp TR, Lemperle SM. ArteFill permanent injectable for soft tissue augmentation: II. indications and applications. Aesth Plast Surg. 2010;34:273-86. doi: https://doi.org/10.1007/s00266-009-9414-o
64. Lemperle G, Morhenn VB, Pestonjamasp V, Gallo RL. Migration studies and histology of injectable microspheres of different sizes in mice. Plast Reconstr Surg. 2004 Apr;15:113(5):138090. doi: https://doi.org/10.1097/01.prs.ooo0112764.22839.7a

65. Cohen SR, Berner CF, Busso M, Gleason MC, Hamilton D, Holmes R, et al. ArteFill: A long-lasting injectable wrinkle filler material-summary of the U.S. Food and Drug Administration trials and a progress report on 4- to 5-year outcomes. Plast Reconstr Surg. 2006 ;118 (3 Suppl):64S-76S. doi: https://doi.org/10.1097/01.prs.0000234873.00905.a4

66. Lebon Laboratório. Linnea Safe [bula]. Porto Alegre; 2018.

67. Vargas AF, Amorim NG, Pintaguy I. Complicações tardias dos preenchimentos permanentes. Rev. Bras. Cir. Plást. 2009 Jan-Mar; 24(1):71-81.

68. Dornelas MT, Corrêa MPD, Netto GM, Barra FML, Alves SGS, Dornelas MC, et al. Bioplastia na lipodistrofia de pacientes com HIV/AIDS. Rev. Bras. Cir. Plást. 2012;27(3):387-91.

69. Kurimori KT, Mendes M, Milcheski DA, Monteiro AA, Gemperli R. Complicação grave do uso irregular do PMMA: relato de caso e a situação brasileira atual. Rev. Bras. Cir. Plást. 2019;34(1):156-162. doi: https://doi.org/10.5935/2177-1235.2019 RBCPoO25

70. Parada MB, Cazerta C, Afonso JPJM, Nascimento DLS. Manejo de complicações de preenchedores dérmicos. Surg Cosmet Dermatol. 2015;8(4):342-51. doi: https://doi.org/10.5935/ scd1984-8773.201684897

71. Ibrahim O, Dover JS. Delayed-Onset nodules after polymethyl methacrylate injections. Dermatol Surg. 2017;44(9):1236-8. doi: https://doi.org/10.1097/DSS.0000000000001405

72. Bringel DM, Bomm L, Azevedo AC, Souto R, Fonseca JC. Complicação de preenchimento cutâneo após tratamento de hepatite C com interferon e ribavirina. Surg Cosmet Dermatol. 2012;4(3):271-3. 